\title{
Active methodologies and teaching performance: a necessary relationship in the field of education
}

\begin{abstract}
Luis, M. Isabel ${ }^{a}$; de la Torre, Tamara ${ }^{b}$; Huelmo, Jonathan ${ }^{c}$; Llamazares, M. Camino ${ }^{\text {; }}$; Ruiz, Esther ${ }^{\mathrm{e}}$; Prieto, Carlos ${ }^{\mathrm{f}}$; Palmero, Carmen'; Jiménez, Alfredo ${ }^{\text {h }}$

${ }^{\mathrm{a}}$ Department of education sciences, University of Burgos Spain, ${ }^{\mathrm{b}}$ Department of education sciences, University of Burgos Spain, ${ }^{\mathrm{c}}$ Department of education sciences, University of Burgos Spain, ${ }^{\mathrm{d}}$ Department of Health Sciences , University of Burgos Spain, ${ }^{\mathrm{e}}$ Department of Specific Didactics, University of Burgos Spain, ${ }^{\mathrm{f}}$ Development area, Suara Coop, Spain, ${ }^{\mathrm{g}}$ Department of Health Sciences, University of Burgos Spain. ${ }^{\mathrm{h}}$ Department of Health Sciences, University of Burgos, Spain.
\end{abstract}

\begin{abstract}
In the present communication, we present the project developed within the Teaching Innovation Group (APAC) of the Faculty of Education at the University of Burgos: "Active Methodologies and Teacher Performance: a road towards inclusion in the classroom". The principal objective of this project is to contribute empirical evidence on the impact that the use of active methodologies has on teaching performance in the classroom. Its results are the basis for the transformation of initial teacher training, because Universities are responsible for training the teachers who will be at the forefront of schools in the $21^{\text {st }} \mathrm{c}$. They have therefore to be offered access to the resources in their initial and lifelong education that permit change, allowing them to construct the paradigm of inclusive, sustainable, and quality education.
\end{abstract}

Keywords: active methodologies; teaching performance; education. 


\section{Introduction}

From the international perspective, organizations such as UNESCO, OECD, and EU, among others, urge universities to instigate profound change in both the initial and the lifelong education of future teachers. They do so because the educational paradigm is evolving rapidly, and the teacher as the promotor of those changes acquires a special and very relevant leading role in the quality of teacher training (Communication from the European Commission, 2010; COTEC, 2016; OECD, 2015; Porte \& Stern, 2017; UNESCO, 2016). Thus, aspects related to initial teacher training are underlined, within the configuration of national educational policies, along with the need to develop and to introduce changes in their training, so that teachers can take the lead in the schools of the 21st c. (Furlong, Cochran-Smith \& Brennan, 2013; Monarca \& Manso, 2015 Manso \& Monarca, 2016).

Universities, as the institution that offers the highest level of training, are responsible for initiating the process of change in the initial training of teachers. The competences that are at present required from teachers therefore have to be included in their teaching/learning processes. The Dirección General de Calidad, Innovación y Formación del Profesorado de la Junta de Castilla y León [General Directorate of Quality, Innovation, and Training of Teaching Staff of the Regional Government of Castile and Leon] has developed the Model of Professional Teaching Competences, based on current regulations as well as on guidelines and specifications from the European context and from Universities with responsibility for teacher training (Dirección General de Calidad, Innovación y Formación del Profesorado, 2011). Ten competences are specified in this model for teaching performance: A. Scientific competence; B. Intra- and inter-personal competences; C. Didactic competence and attention to diversity; D. Organizational competence and management of the educational centre; E. Competence in classroom behaviour management; F. Competence in team work; G. Competence in innovation and improvement; H. Linguistic-communicative competence; I. Digital competence (ITCs); J. Socio-relational competence.

Training for Teaching Innovation Groups (Grupos de Innovación Docente) (GID) is promoted within the University of Burgos in the form of refresher courses for teaching in the university context. The GID Act to Learn, Learn to Act (Actuar para aprender, aprender para actuar) (APAC) was launched at the Faculty of Education in 2016. It is formed of teachers from the University of Burgos and teachers active in non-university contexts, with the objective of investigating teaching innovation in the field of active methodologies and to transmit progress in those fields to future teachers. Thus, in October 2017, the project "Active Methodologies and Teaching Performance: a road towards inclusion in the classroom" was presented to the Provincial Directorate of Education of Burgos and approved in November 2017. Understanding as an active methodology a methodological 
principle that considers as its main objective the participation of the student in their learning (García, Y., Herrea, García, M.A., \& Guevara, 2015; Jiménez, 2009; Llinares, 2013; Rodríguez \& Grilli, 2016).

The objective of the present Communication is to present the project as an example of research in the non-university educational context that can lead to innovation in the processes and the contents of initial teacher training developed at university.

\section{Work objectives}

The project on Active Methodologies is centred on analysing the correlation that exists between the use of approaches that strengthen the development of inclusive practices through active methodologies, the improvement of teaching performance, and the degree of motivation among students, encapsulated in the following work objectives:

1.To evaluate the degree of impact of the training actions in the context of methodologies that favour interaction, improving professional teaching competences.

2.To establish the correlation between the development of aspects of teaching competences linked to the inclusive paradigm of education and the improvement of social relations in the classroom.

3.To determine the causal relation between teacher training in cooperative methodologies and the levels of student success, taking into account the personal conditions of students at the outset.

The proposed objectives are dependent on the following working hypotheses:

1.Teacher knowledge of methodologies related with the inclusive paradigm of education, which encourages student participation and involvement, promoting higher levels of teaching competencies. (Hp 1)

2.Teacher training on methodological approaches that favour interaction between students, that reduce the frequency and/or intensity of inappropriate behaviour within the groupclass, and that allow a change in the general culture of the centre that will assist the development of inclusive practices. (Hp 2)

3.The success of students in Infant, Primary, and Secondary School Education correlates in a positive way with lifelong training of teachers. (Hp3) 


\section{Methodology}

This investigation uses an interpretative paradigm and a mixed, quantitative, and qualitative methodology with which to corroborate the hypotheses proposed in the study.

Working hypotheses and Evaluation Instruments

Hp1: The knowledge of teachers on methodologies related to the inclusive educational paradigm, which encourages student participation and involvement, promotes higher levels of teaching competences.

Instrument: TPT, TEA Test of Personality. Authors: S. Corral, A. Pamos, J. Pereña and N. Seisdedos.Year: 2001. Editorial: TEA Editions. Application: Individual and collective

Scope of application: Adolescents and adults specifically in the field of working life. In particular, the working practice of the educational professional is considered. Its variables can impact on adaptation and on the success of educational activity, above all the specific features of responsibility and mental openness.

Duration: Variable, around 30 minutes, or less in accordance with the reading skills of the participant.

End purpose: Evaluate 15 personality features and competences grouped into 4 general factors and dimensions. It also has an index of success in professional life and a scale of sincerity.

Rating: General adult population, in centile and standard S scores, among men and woman and a normative balanced sample of both sexes.

Bearing in mind that according to the European model the competences of teachers are ten (scientific competence, intra and interpersonal competence, didactic competence, organizational and management competence, competence in managing coexistence, communicative and linguistic competence, digital competence, social competence relational, competence in teamwork, competition in innovation and improvement), with the TPT instrument we can measure a large part of them, in particular:

B. Intra- and inter-personal competences (way of being and treating others well).

C. Didactic competence (Process of teaching-learning and its management)

D. Organizational competence and management of the Centre

E. Behaviour management competence

F. Team work competence

G. Innovation and improvement competence

J. Socio-relational competence 
Hp 2: The training of teachers in methodological approaches that favour interaction between students will reduce the frequency and/or intensity of inappropriate behaviours within the group-class and permit a change in the general culture of the centre that will favour the development of inclusive practices.

- Sociogram designed ad hoc, with the objective of detecting the different relational dynamics present in the classroom, placing special emphasis on identifying those students that are in marginalized situations.

- Frequency and seriousness of misbehaviour reports that have been registered at the centre over the 2015/16 and 2016/17 academic years.

- Frequency and type of misbehaviour that infringes the disciplinary code of the educational centre registered on the software application of the Education Board CONV over the academic years 2015/16 and 2016/17.

- Self-organized discussion and interview group with a sample of different educational agents involved in the lifelong training process that is evaluated.

- Index for inclusion: developing learning and participation in schools (INDEX) by Tony Booth and Mel Ainscow.

Hp 3: The success of students at Infant, Primary, and Secondary School levels correlates in a positive way with the lifelong training of teachers.

- Evaluation sessions of Primary Education, Mandatory Secondary Education and Sixth Form (Pre-University) Education of the different groups of students whose teachers participate in the experiment. The evaluations are conducted under the framework of the model that is specified in Annex IV of Decree 26/2016, of 21st July, which establishes the curriculum and regulates the implantation, evaluation, and development of Primary Education; Annex VIII of Order EDU/362/2015, of 4th May, which establishes the curriculum and regulates the implantation, evaluation, and development of Secondary Education; and Order EDU/363/2015, of 4th May, which establishes the curriculum and regulates the implantation, evaluation, and development of sixth-form studies.

- Minutes and follow-up report of the training activity that teachers implement, according to the model facilitated by the CFIE of Burgos.

- Final Report of the training activity that the teachers implement taking into account the questionnaire on projects of educational innovation contained in the Study on educational innovation in Spain [Estudio sobre la innovación educativa en España] edited by the Ministry of Education. 


\subsection{Analysis of Information}

With a view to analysing the quantitative data, the statistical analysis was done with the SPSS software package v. 22 under Windows XP.

Those analyses will, on the one hand, be descriptive:

a) where the results will be presented through tables and figures that relate to the description of the sample and the average scores obtained by each section of the questionnaire or report.

And, on the other hand, inferential:

b) in which the statistical significance of the differences found in the various items in relation to teaching performance and the degree of student motivation will be analysed. Specifically, the technique of Variance Analysis will be applied for the analysis of the global significance of the differences, followed by an analysis of the coefficients of correlation between the valuation given to all the questionnaire statements.

\section{Expected results}

The present study sets out to determine whether there is a positive correlation in the development of aspects of competence covered in the Model of Professional Competences and the degree of student motivation. In addition, an evaluation procedure is prepared to determine the degree of development in the classrooms of training processes that began in the provincial CFIE of Castile and Leon. Thus, the aim is to find scientific evidence that permits the correlation of successful situations with quality training processes.

Besides, the qualitative analysis is oriented towards demarcating both personal indicators and indicators belonging to the educational community in which the individual is integrated, which makes it possible for certain methodological strategies to be successfully implemented. The overall aim is to encourage the creation of that same situation in other contexts, fostering a generalized implementation of methodological strategies which strengthen the development of inclusive practices, because they favour interaction, creation, metacognition and the commitment of the student.

Finally, this study will start to define the aspects of teacher competences that are primordial to achieve a quality system that fits in with the demands behind the changes that are taking place at a social and economic level; a fundamental aspect in the initial teacher training developed within Universities. 


\section{References}

Communication from the Commission (2010). Europe 2020. A strategy for smart, sustainable and inclusive growth. COM (2010) 2020 final.

COTEC (2016). Informe COTEC 2016: Innovación en España. Madrid, Fundación COTEC para la innovación.

Dirección General de Calidad, Innovación y Formación del Profesorado (2011). Modelo de Competencias profesionales del Profesorado. Junta de Castilla y León

Furlong, J., Cochran-Smith, M., \& Brennan, M. (2013). Policy and politics in teacher education: International perspectives. United Kingdom: Routledge.

García, Y., Herrera, J. I., García, M. Á. \& Guevara, G. E. (2015). Collaborative work and its influence on the development of teaching professional culture. Gaceta Médica Espirituana, 17(1), 60-67.

Jiménez, L. A. (2009). Cuba: the psychopedagogical and methodological Capacitation program: An alt ernative To stimulate cognoscitive competence. Educere, 13(44), 205 214.

Llinares, S. (2013). The development of the "professional noticing" skill in teachinglearning mathematics. Educar em Revista, O(50), 117-133. doi:10.1590/s010440602013000400009

Manso, J. \& Monarca, H. (2016). Concepciones de la OCDE y la Unión Europea sobre el desarrollo profesional docente. Journal of supranational policies of education, $\mathrm{n}^{\mathrm{o}} 5 \mathrm{pp}$. 137-155

Monarca, H. \& Manso, J. (2015). Desarrollo Profesional Docente en el Discurso de los Organismos Internacionales. Revista Española de Educación Comparada, 26, 171-189.

OECD (2015). Skills Strategy Diagnostic Report: Spain. OECD

Porte, M. E. \& Stern, S. (2017). Social Progress Index 2017. Washington, Deloitte.

Rodríguez, E., \& Grilli, J. (2016). Challenges of the collaborative resonance practice model in early teacher training. Educar em Revista, O(62), 199-227.doi:10.1590/01044060.46406

UNESCO (2016). Education 2030. Incheon Declaration and Framework of Action for the implementation of Sustainable Development Goal 4. Ensure inclusive and equitable quality education and promote lifelong learning opportunities for all. París, UNESCO. 